\title{
GRADUAÇÃO/PÓS-GRADUAÇÃO: A BUSCA DE UMA RELAÇÃO VIRTUOSA
}

\author{
Carlos Roberto Jamil Cury
}

\begin{abstract}
RESUMO: $\mathrm{O}$ artigo tem como objetivo indicar, na situação presente das instituições universitárias, a relação entre a graduação e a pós-graduação como forma institucional de preencher a indissolubilidade entre ensino, pesquisa e extensão. As possibilidades de uma relação mútua que fecunde os dois níveis do ensino superior se apóiam em dados do sistema de educação superior, assinala os dispositivos legais sobre o assunto e aponta o que já existe e as lacunas a serem preenchidas.
\end{abstract}

Palavras-chave: Graduação/pós-graduação. Níveis do ensino superior no Brasil. Ensino, pesquisa e extensão.

\section{UNDERGRADUATE/GRADUATE STUDIES: SEEKING A VIRTUOUS RELATIONSHIP}

ABSTRACT: This article aims at giving the reader a vision, in the present Brazilian situation especially of the relation between undergraduate and graduate studies as an institutional form to maintain the indissociability between teaching, research and extension. The possibilities of a mutual relationship that may enrich both levels are highlighted on the ground of data on the higher education system. The text also reviews the legal provisions existing on the matter and. identifies the gaps that should be filled

Key words: Undergraduate/graduate studies. Levels of the Brazilian Higher Education. Teaching, research and extension.

\footnotetext{
* Professor da Pontifícia Universidade Católica de Minas Gerais (PUC-MG).

E-mail: crjcury.bh@terra.com.br
} 


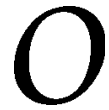

ensino superior qualificado cumpre importante função estratégica para o desenvolvimento do país, das instituiçóes e das pessoas. A graduação e a pós-graduação são âmbitos específicos do ensino superior, devendo cumprir finalidades próprias e complementares. Como afirma, de modo peremptório, o Plano Nacional de Educação (PNE):

Nenhum país pode aspirar a ser desenvolvido e independente sem um forte sistema de educação superior. Num mundo em que o conhecimento sobrepuja os recursos materiais como fator de desenvolvimento humano, a importância da educação superior e de suas instituições é cada vez maior. Para que estas possam desempenhar sua missão educacional, institucional e social, o apoio público é decisivo.

A relação entre ambas pode ser vista de vários ângulos. Há aquele da trajetória de cada qual na história da educação brasileira, há o das suas finalidades, o do ordenamento jurídico e o planejamento próprio e interno de cada instituição de ensino superior, entre tantos outros. Este texto pretende sobretudo focar o ângulo relativo à formação exigida para o exercício do magistério no ensino superior e aos aspectos legais, sem deixar de propor sugestões para uma interação mais dinâmica entre graduação e pós-graduação tendo em vista a melhoria da qualidade da educação superior. Mas não se pode deixar de afirmar que essa relação só se cumpre de modo pleno quando o ensino superior se reveste da figura universidade.

A Constituição Federal de 1988 privilegia a figura universidade por meio de um artigo próprio: o 207. Ao tratar da definiçãao de universidade, o artigo 207 não pede que o ensino se isole na graduação ou que a pesquisa seja propriedade privada da pós-graduação. A pesquisa, o ensino e a extensão são indissociáveis na universidade e, por isso mesmo, as três funções são institucionais no seu todo e, como funções permanentes, devem estar presentes no conjunto universitário. Por seu lado, o ser professor não resume em si apenas o docente capaz do ensino, mas inclui o pesquisador dotado de condições para promover investigações e para absorver resultados da pesquisa. Por sua vez, o ser pesquisador não é suficiente para ser docente. A formação didático-pedagógica é necessária para a formação de geraçôes de estudantes qualificados, muitos dos quais voltados para as licenciaturas responsáveis pela formação de outros docentes para atuar na educação básica. Por isso essa relação deve consistir num círculo virtuoso em que as especificidades de cada qual se beneficiem mu- 
tuamente seja para a qualificação interna da universidade, seja para a formação de profissionais compromissados, críticos e competentes para o desenvolvimento do país.

A graduação, tardia na sua origem e constituição em nosso país, já que remonta à chegada de D. João VI ao Brasil, teve sempre como componente dominante o ensino. $\mathrm{O}$ ensino, por ser o repositório da memória do conhecimento acumulado pela humanidade, torna-se a base para se ir do conhecimento consolidado para o ainda não conhecido. Será tarefa da pesquisa trazer à tona as descobertas e os avanços que ela propicia. Do mesmo modo, é função do ensino, como diria Gramsci, socializar verdades já conhecidas e torná-las patrimônio de todos. Neste sentido, a graduação tem e teve o ensino como seu componente predominante. ${ }^{1}$

A graduação, como componente do ensino superior, incorpora, de um lado, essa necessária herança da humanidade a ser transmitida pelo ensino e, por outro lado, vê-se potencializada pela incorporação do novo que a pesquisa revela. Neste sentido, a graduação tem como conceito regulador o princípio da preservação enriquecida, cujo ensino se volta para uma profissionalização, compromissada e competente, necessária à inserção profissional no mundo atual. Esta vocação constituída pelo caráter formativo-profissionalizante permite uma flexibilidade organizacional mas não tão elevada quanto a da pós-graduação.

A pós-graduação, como componente do ensino superior, eleva o ensino nela ministrado pela contínua atualização de conhecimentos propiciada pela pesquisa, garantida pela utilização de uma metodologia científica em ação e pela circulação de múltiplos pontos de vista. Por conseqüência, a pós-graduação tem como conceito regulador o princípio da inovação por meio da produção de conhecimentos expressa na pesquisa. Na pós-graduação, o componente da investigação é dominante e esta não pode ver-se privada de portais científicos, laboratórios, bibliotecas atualizadas e número mais reduzido de estudantes. ${ }^{2}$

A pós-graduação sistemática tem uma origem recente ${ }^{3}$ e, como promotora de graus acadêmicos, usufrui alto grau de flexibilidade organizacional, articulada com possibilidades interdisciplinares. Além disso, o rigoroso processo de reconhecimento de programas imprimiu um ritmo ordenado na expansão da pós-graduação.

A comunidade científica no Brasil deve muito ao desenvolvimento da pós-graduação universitária. Desde o seu início, houve empenho por 
parte dos administradores acadêmicos e dos gestores governamentais em ampliar o número de pesquisadores e docentes qualificados. A consecução de uma "massa crítica" foi objeto claro não só dos Planos Nacionais de Pós-Graduação, mas também de uma atuação consciente e efetiva do próprio Estado. Graças a essa política, o Brasil conseguiu não só formar um grande número de pós-graduados como também constituir um sistema institucionalizado de pós-graduação de alta qualidade. Sobressaise, nesse caso, a sistemática de coleta de informações e a avaliação de desempenho dos docentes, dos cursos (por áreas e subáreas de conhecimento) e das instituições por meio de atuação dos pares. Tal política pública propiciou uma realidade bem-sucedida logo convertida em verdadeiro sistema com um reconhecimento nacional e internacional de sua qualidade. Nesse processo especial destaque se confere aos processos de avaliação levados adiante pela Coordenação de Aperfeiçoamento de Pessoal de Nível Superior (CAPES). Cooperaram para tal tanto as bolsas concedidas por esta fundação, pelo Conselho Nacional de Desenvolvimento Científico e Tecnológico (CNPq) e também por algumas Fundaçōes Estaduais de Amparo à Pesquisa (FAPs), quanto outros programas de apoio e de fomento fornecidos por tais agências.

Graças a esse sistema, o Brasil vem titulando, segundo os dados gerais de 2003, por meio de mais de 2,6 mil cursos, perto de $8 \mathrm{mil}$ doutores e de 28 mil mestres por ano. Desses últimos, perto de 9 mil continuam seus estudos e pesquisas no doutorado. São mais de $40 \mathrm{mil}$ estudantes matriculados no doutorado e de 72 mil matriculados no mestrado. As projeções para o futuro indicam, pelo menos, a manutenção de um crescimento constante qualificado.

Confronte-se esses dados de 2003 com o início da pós-graduação quando, no final dos anos de 1960, havia perto de 100 cursos e de 2 mil estudantes. Em 1990, a pós-graduação nacional formava perto de 1,5 mil doutores e 5,6 mil mestres por ano. Já em 1996, ela formava 3 mil doutores e 10 mil mestres por ano em números redondos. Trata-se de um esforço bem-sucedido e que atende não só a determinações legais mas também acaba por canalizar prestígio às universidades.

É verdade que ainda há muitas assimetrias estaduais na oferta da pós-graduação. De acordo com dados obtidos com a CAPES, em 1.570 programas existentes em 2002, pode-se verificar que São Paulo absorve 526 programas $(33,5 \%)$ de pós-graduação, seguido do Rio de Janeiro 
com 225 (14,3\%), Rio Grande do Sul com 156 (9,9\%) e Minas com 146 (9,3\%). Tocantins, Acre, Amapá e Roraima não possuíam nenhum programa. Alagoas possui $8(0,51 \%)$, Maranhão $6(0,38 \%)$, Piauí 5 $(0,32 \%)$, Mato Grosso e Sergipe, ambos com 4 programas $(0,25 \%)$. Paraná tem 96 programas $(6,1 \%)$; Pernambuco, com 62 programas, concentra 3,9\%; Santa Catarina, com 52 programas, responde por $3,3 \%$ dos programas. O Distrito Federal tem 48 programas, o que significa 3,0\%. Bahia tem 46 programas, isto é, 2,9\%. Ceará tem 41, o que dá 2,6\%. Rio Grande do Norte, com seus 30 programas, tem 1,9\%. Pará tem 26 programas, Paraíba 24 e Goiás 22, respectivamente $1,6 \%, 1,5 \%$ e $1,4 \%$. Amazonas e Mato Grosso absorvem cada um 14 programas e Espírito Santo 13, o que dá, respectivamente, 0,89\% para os dois primeiros e $0,83 \%$ para o terceiro. Mais do que assimetrias regionais, estas se revelam nos dados por estados. Ainda que se considere os PIBs estaduais e a demografia de cada qual, o número de estudantes na educação básica e o número de instituições de ensino superior (o que conduz a diferenciações), é preciso não esquecer de que o princípio federativo exige mais equilíbrio e o desenvolvimento regional é um princípio constitucional.

Quando se somam os estados por regiōes geográficas, os dados assim se apresentam em número de programas: Sudeste: 910; Sul: 304; Nordeste: 226; Centro-Oeste: 88 (DF com 48); Norte: 42. Mas não resta dúvida quanto ao aparato administrativo formador: são 1.351 programas no setor público e 219 no setor privado. Se considerarmos, no ano de 2002, um número de 129.603 pós-graduandos, 109.592 estão no setor público $(84,6 \%)$ e 20.011 no setor privado $(15,4 \%)$.

Neste sentido, a pós-graduação tem sido um esteio indispensável à formação de recursos humanos de alta qualificação e à produção de conhecimentos necessários para o desenvolvimento científico e tecnológico do país. Esse desenvolvimento possibilita ao país a atualização de saberes e a busca sistemática e metódica do conhecimento de ponta. Para tanto, esse esforço combinou o crescimento de programas dentro do país com uma grande internacionalização de formação doutoral. Essa internacionalização, conquanto mais concentrada em alguns países, vem se diversificando e formando doutores, atualizando-os pelos estudos de pós-doutorado e fazendo com que nossos pesquisadores e, por eles, nossas instituições possam se comunicar com seus pares congêneres no país e no exterior. 
O ensino superior teve, na vertente da graduação, sobretudo a partir de 1997, um crescimento inaudito como se verá mais abaixo. Essa expansão, em sua maior parte, é detida pela rede privada. ${ }^{4}$

Do ponto de vista administrativo, segundo os dados do Instituto Nacional de Estudos e Pesquisas Educacionais (INEP), em 2002, as 162 universidades existentes estão assim divididas administrativamente: 43 universidades federais, 31 estaduais, 4 municipais e 84 privadas (58 sem fins lucrativos e $28 \mathrm{com}$ fins lucrativos). São 77 centros universitários, dos quais 74 ficam com a rede privada (47 com fins lucrativos e 27 sem fins lucrativos), 1 municipal e 1 federal. As faculdades integradas, em número de 105, subdividem-se em 102 instituições privadas ( 85 com fins lucrativos, 17 sem fins lucrativos) e 3 municipais. As 1.240 instituições isoladas compreendem 80 públicas (7 federais, 25 estaduais e 48 municipais) e 1.160 privadas (943 com fins lucrativos e 217 sem fins lucrativos). ${ }^{5}$

Esse crescimento conta com a notável pressão advinda da expansão do ensino médio público. Com efeito, se em 1991, segundo o INEP, havia perto de 3,8 milhões de matrículas no ensino médio como um todo e perto de 670 mil concluintes, em 2000 as matrículas sobem para mais de 8 milhões e o número de concluintes avulta para próximo dos 1,9 milhão. Ao mesmo tempo, se, em 1991, havia uma oferta de perto de 520 mil vagas no ensino superior, em 2000 elas haviam subido para pouco mais de 1,1 milhão de vagas nos processos seletivos.

Essas vagas, porém, conheceram pressões vindas de outros vetores além daquele do ensino médio. Há que se refletir sobre o significado dos dados estatísticos. A configuração mundial do sistema capitalista em termos de novos modos de produção e de divisão internacional do trabalho também deve ser considerada. Hoje mudanças significativas ocorrem em todo o planeta porque a configuração da informação em rede o coloca em dimensões diferenciadas de aspectos que, até há pouco tempo, eram considerados fundamentais. Um contínuo recuo da força física e do próprio valor das matérias-primas em favor do avanço da força intelectual e das novas formas de composição produtiva evidencia o fim estrutural de muitos postos de trabalho. Ao mesmo tempo, novos serviços comparecem à cena social com exigências reveladoras de uma nova forma de mais-valia: a mais-valia intelectual. Daí decorre o papel significativo e estratégico do ensino superior em face das novas 
postulações da cidadania, do desenvolvimento dos países e do universo das relaçóes sociais.

Outro ponto importante nessa expansão do ensino superior foi o eixo da flexibilidade posto na recente legislação educacional brasileira. A diminuição de vários requisitos burocráticos para a autorização de funcionamento, a maior autonomia das instituições na criação de cursos, a capacidade de as instituições credenciadas emitirem seus diplomas, o fim do registro no MEC condicionaram a atuação dos órgãos normativos e dos órgãos executivos dos sistemas. Esses passaram a fazer exigências mais módicas para a autorização de abertura de cursos e deixaram para o eixo da avaliação uma análise ex post da atuação das instituições. Em certo sentido, a legislação existente vai da negação de um sistema nacional de educação à afirmação de um sistema nacional de avaliação. Este sistema está literalmente nomeado no artigo $87, \S 3^{\circ}$, IV, da Lei de Diretrizes e Bases da Educação Nacional (LDB).

A avaliação tornou-se o eixo nodal da LDB, esperando-se que ela não só seja o canal mais importante da prestação de contas para a comunidade dos resultados de desempenho como também o móvel para políticas de apoio, fomento dos cursos e das instituiçôes e mesmo para o descredenciamento das instituições medíocres.

É de se registrar que, ao passo que o processo de avaliação da pósgraduação se implantou nos anos de 1970 , o processo na graduação iniciou-se após a Lei n. 9.131/95, seguida da Lei n. 9.394/96, do Decreto n. 3.860/01 e agora pela Lei n. 10.861/04. ${ }^{6}$

Em decorrência da necessidade de um quadro de conjunto e de acordo com os dados do INEP, em 1991, as instituiçóes de ensino superior abrigavam 1.565.056 matrículas em cursos de graduação. Desse total, nesse ano, 959.320 matrículas estavam na rede privada, representando $61 \%$ dessas matrículas. Eram 671 instituições privadas de ensino superior, representando $75 \%$ do total das 893 instituições de ensino superior (IES).

Em 2002, consoante os dados do INEP, as matrículas de graduação, no conjunto dos sistemas de ensino e das respectivas redes, contavam com 3.479.913 alunos. Desses, 2.150.659 estavam em universidades, 430.315 em centros universitários, 179.707 em faculdades integradas, $676.053 \mathrm{em}$ instituições isoladas e 43.179 em centros tecnológicos. ${ }^{7}$ 
A rede privada cresceu e predomina, em números absolutos e relativos, segundo os dados do INEP em 2002, contando com 2.428.258 matrículas, ou seja, 69,7\%. E em número de instituiçōes, das 1.637 IES, 1.442 estavam vinculadas ao setor privado, ou seja, 88\%.

Por sua vez, as funções docentes em exercício, de um total de 133.135 no conjunto dos sistemas de ensino, considerado o grau de formação, contavam, em 1991, com 29.046 mestres $(21,81 \%)$ e 17.712 doutores $(13,30 \%)$.

Em 2000, das 183.194 funções docentes, 54.619 incluíam-se no nível de mestrado $(29,81 \%)$ e $39.522(21,57 \%)$ no de doutorado.

Em 2001, nas 219.947 funções docentes no ensino superior brasileiro como um todo, tínhamos 72.978 mestres $(33,17 \%)$ e 46.133 doutores $(20,97 \%)$. Com relação ao conjunto das funções docentes no ensino superior, o setor público conta com 13,59\% dos mestres e com 15,27\% de doutores. Ante as mesmas 219.947 funções docentes do ensino superior brasileiro, o setor privado abriga $22,54 \%$ de mestres e $7,56 \%$ dos doutores, aproximando-se do terço exigido por lei.

Se considerarmos as funções docentes de cada segmento, o quadro assim se mostra: o segmento público apresenta-se com 90.950 funções docentes. Com relação a essas funções docentes, 27.446 são de mestres $(30,17 \%)$ e 30.855 são de doutores $(33,92 \%)$.

Por sua vez, o segmento privado como um todo se apresenta com 128.997 funções docentes, das quais 45.532 são de mestres $(35,29 \%)$ e 15.278 são de doutores $(11,84 \%)$. Isso significa que, em face do seu próprio conjunto, a rede privada ultrapassa os $33 \%$ exigidos pela LDB, cujo artigo 88 prevê 8 anos para que universidades cumpram o estabelecido nos incisos II e III do artigo 52 da mesma lei.

Dentro desse conjunto, os dados manifestam, nas instituições privadas sem fins lucrativos, 64.796 funçôes docentes, das quais 23.435 mestres $(36,16 \%)$ e 8.647 doutores $(13,34 \%)$. As instituições lucrativas, dentro de um todo de 64.201 funções docentes, incluem 22.097 mestres $(34,41 \%)$ e 6.631 doutores $(10,32 \%)$.

Assim, mesmo as instituições privadas não-universitárias, com 44.509 funçōes docentes, abrigam 18.605 com mestrado e doutorado, ou seja, perto de $42 \%$ do seu total. É certo que esses porcentuais são gerais e seria preciso verificar como eles se desdobram por regiōes, por áreas e subáreas, e sobretudo por instituições individualmente consideradas. ${ }^{8}$ 
O crescimento de mestres e doutores, em quase 10 anos, em sua maior parte graças ao sistema nacional de pós-graduação, contou também com o constrangimento legal das Diretrizes e Bases da Educação Nacional (LDB), Lei n. 9.394/96, que, em seu artigo 52, exige que uma instituição para aceder à prerrogativa de universidade tenha produção intelectual institucionalizada, um terço do corpo docente, pelo menos, com mestrado e doutorado e um terço com tempo integral. ${ }^{9}$

Se os dados relativos à qualificação apresentam indicadores de crescimento e mesmo de atendimento dos patamares mínimos exigidos pela LDB, o mesmo não ocorre com o critério de tempo integral.

De acordo com o artigo 9o do Decreto n. 3.860/01, o tempo integral como regime de trabalho está assim definido:

Para fins do inciso III do art. 52 da Lei 9.394, de 1996, entende-se por regime de trabalho docente em tempo integral aquele que obriga à prestação de quarenta horas semanais de trabalho na mesma instituição, nele reservado o tempo de pelo menos vinte horas semanais destinado a estudos, pesquisa, trabalhos de extensão, planejamento e avaliação.

De acordo com o INEP, o conjunto das IES abriga 90.631 funções docentes com tempo integral dentro do universo de 219.947 funções docentes, ou seja, $41 \%$ do total geral. As universidades, no seu todo, contam com 148.219 funções docentes, sendo que 79.100 estão com tempo integral, ou seja, 53,36\%. Mas, dessas 79.100 funções docentes, 64.605 são de universidades públicas para um total de 82.461 funções docentes nessas últimas.

As universidades privadas contam com 65.758 funções docentes, das quais só 14.495 estão em regime integral, o que equivale a $22,04 \%$. Se no conjunto das universidades privadas ainda se está abaixo do que prevê a legislação, dessas 14.495 funções docentes, 10.504 estão naquelas universidades sem fins lucrativos. Portanto, resta bastante a ser efetivado no âmbito das instituições universitárias privadas, uma vez que o regime de trabalho e a dedicação aos cursos implicarão a distribuição do tempo entre graduação e pós-graduação.

Além disso, é preciso conferir em que medida os processos de avaliação, como o do então Exame Nacional de Cursos ("Provão"), as condições de oferta e as condições da docência impactaram as instituições em matéria de estímulo para a continuidade da qualificação dos professores e de sua dedicação aos cursos. ${ }^{10}$ 
Por sua vez, apesar da rarefação dos recursos financeiros, a universidade pública vem mantendo, a duras penas, a sua tradição de investimento em pesquisa, a articulação com o ensino e a busca incessante para se manter como um pólo de excelência. Cumpre, então, lembrar o que assevera o artigo 218 da Lei Magna:

O Estado promoverá e incentivará o desenvolvimento científico, a pesquisa e a capacitação tecnológicas.

$\$ 1^{\circ}$. A pesquisa científica básica receberá tratamento prioritário do Estado, tendo em vista o bem público e o progresso das ciências.

$\$ 2^{\circ}$. A pesquisa tecnológica voltar-se-á preponderantemente para a solução dos problemas brasileiros e para o desenvolvimento do sistema produtivo nacional e regional.

$\$ 3^{\circ}$. O Estado apoiará a formação de recursos humanos nas áreas de ciência, pesquisa e tecnologia, e concederá aos que dela se ocupem meios e condiçôes especiais de trabalho.

Apesar de orçamentos contingenciados, os programas de apoio e fomento da CAPES e do CNPq, tais como os estudos pós-doutorais, estágios e a presença em eventos científicos, representam uma incitação à busca de patamares superiores de qualificação. E não se podem negar os esforços endógenos dos docentes e pesquisadores em socializar sua produção por meio de artigos, capítulos de livros e livros.

Se o poder público não investe na expansão da sua rede física, se a demanda por ensino superior é crescente, se o reconhecimento de instituições isoladas ou integradas como universidade está vinculado a ir além de um terço de mestres/doutores, os programas de pós-graduação passam a ocupar um lugar crítico na organização nacional da educação superior.

Crítico porque a consolidação da pós-graduação nem sempre se deu de modo integrado com o conjunto da instituição ou resultou em aperfeiçoamento satisfatório da graduação. Há um efeito-correlação entre essas duas etapas do ensino superior. Em uma região ou cidade em que se tem um vasto número de mestres e doutores, a atuação destes tende a filtrar-se para a graduação. $\mathrm{O}$ mesmo processo, contudo, em regiōes com fraco equilíbrio entre as etapas, tende a deixar a relação mais tênue.

Esse papel crítico assume também outro significado pela natureza intrínseca da pesquisa, que, investindo contra certezas absolutas, impõe 
o distanciamento de posições dogmáticas e faz avançar o conhecimento no conjunto das áreas. É um lugar crítico pelo papel enfático na qualificação do corpo docente em face da limitação de meios e recursos para uma ampliação qualificada. E como há um meticuloso processo seletivo para se entrar em programas recomendados e um rigoroso processo avaliativo para se ter programas recomendados, tanto a demanda por cursos é maior do que a oferta quanto o número de novos programas recomendados fica abaixo dos pedidos cadastrados. Afinal, o crescimento desordenado do ensino superior (graduação) não conta, em todas as instituições, com professores qualificados para concorrer a vagas em programas de pós-graduação recomendados e avaliados. Resulta daí a busca apressada por cursos e programas, no país ou no exterior, que não só não têm a recomendação dos órgãos nacionais qualificados como também emitem falsos diplomas, já que não possuem validade nacional.

Por sua vez, muitos estudantes vindos do ensino médio chegam mal preparados à universidade e muitos professores se fizeram tais sem ter uma adequada preparação para o magistério superior. Daí a existência, muitas vezes, de uma "dupla rede" no ensino superior: na graduação a docência, na pós-graduação a pesquisa. $\mathrm{O}$ fato de a pós-graduação contemplar como foco a pesquisa tem levado, muitas vezes, a um centramento no objeto específico da pesquisa e na relação com o orientador. Com isso fica comprometida a expectativa de que a pós-graduação traria naturalmente avanços qualitativos para a graduação. Houve avanços inegáveis, como no caso da melhoria da qualificação dos docentes, mas a circulação virtuosa com alteraçōes no padrão de qualidade da graduação ainda tem um bom caminho a ser percorrido. Assim, a pesquisa deve estar presente no ensino superior e, como bem estabelece o Plano Nacional de Educação (PNE), em sua meta de n. 18, no capítulo do ensino superior, é preciso "Incentivar a generalização da prática da pesquisa como elemento integrante e modernizador dos processos de ensino-aprendizagem em toda a educação superior, inclusive com a participação de alunos no desenvolvimento da pesquisa”.

Ao mesmo tempo, buscando a meta de um círculo virtuoso entre graduação e pós-graduação, a LDB dispõe, no artigo 57, que "Nas instituiçōes públicas de educação superior, o professor ficará obrigado ao mínimo de oito horas semanais de aulas".

Ao mesmo tempo, a Lei n. 9.678/98 instituiu a Gratificação de Incentivo à Docência (GED), articulando-a com o artigo 57 da LDB. ${ }^{11}$ E o 
próprio Plano Nacional de Educação, no capítulo da Educação Superior, assinala em suas Diretrizes:

É igualmente indispensável melhorar a qualidade do ensino oferecido, para o que constitui instrumento adequado a institucionalização de um amplo sistema de avaliação associada à expansão dos programas de pós-graduação, cujo objetivo é qualificar os docentes que atuam na educação superior.

Vê-se, pois, a importância de um Projeto de Desenvolvimento Institucional (PDI) que, como fator de responsabilidade da instituição de ensino superior, articule a graduação e a pós-graduação de modo que essa última possa se impor como formadora de pessoal qualificado para atuar no conjunto da instituição e efetivar, com qualidade, as exigências do artigo 43 da LDB. De um lado, há a necessidade de realização de pesquisas que propiciem o avanço do conhecimento em instituiçōes que queiram a prerrogativa universitária, e naquelas instituições que ostentam o título de centro universitário, ao menos a instauração sistemática de um clima de pesquisa, já que a excelência do ensino pressupóe a atualização de conhecimentos. ${ }^{12}$ A pesquisa deve ser institucionalizada, ou seja, estar presente de modo consolidado no todo da instituição. Daí não segue que todos os docentes devam ser obrigatoriamente pesquisadores, embora não se conceba um docente que não alimente seu fazer pedagógico com os resultados de pesquisas expressos em publicações.

Um campo que significa um avanço com resultados palpáveis de integração entre pesquisa e ensino é o da iniciação científica ou similar. Tal programa introduz, sob orientação docente, o estudante à pesquisa desde a graduação e possibilita maior circulação entre a graduação e a pós-graduação. Muitos estudantes de iniciação científica ainda se tornam solidários com os colegas que não dispõem dessa bolsa, começam a desenvolver trabalhos conjuntos com os seus orientadores chegando mesmo a publicações em parceria. Não raro esses estudantes criam um espaço propício para bem-sucedidas seleções para a pós-graduação stricto sensu. Contudo, as bolsas de iniciação científica e outros similares, se funcionarem de modo isolado e/ou pouco expandido, produzem avanços mas sem a qualidade de uma integração institucional mais ampla.

Outro programa bem-sucedido na busca de uma "cultura institucional de pesquisa" é o relativo à monitoria. Ele conta inclusive com um artigo próprio na LDB, o artigo 84 , que dispõe: 
Os discentes da educação superior poderão ser aproveitados em tarefas de ensino e pesquisa pelas respectivas instituições, exercendo funções de monitoria, de acordo com seu rendimento e de seu plano de estudos.

Esse clima institucional de pesquisa favorece, por exemplo, a publicação, por parte dos docentes, de textos didáticos voltados para o ensino tanto superior quanto para o da educação básica. Esse contato com a pesquisa e seus produtos obriga o docente a um processo de atualização, de verificação da obsolescência de aspectos do conhecimento e também à presença em eventos de natureza científica.

Por isso a Lei de Diretrizes e Bases da Educação Nacional, em seu artigo 66, assevera: "A preparação para o exercício do magistério superior far-se-á em nível de pós-graduação, prioritariamente em programas de mestrado e doutorado”.

A LDB reconhece que o exercício do magistério superior não pode ser um campo para diletantes ou mal preparados. A docência é um campo profissional e o exercício do magistério conta, de longa data, com um saber que lhe é próprio. O Título VI da LDB versa sobre os Profissionais da Educação. Daí a exigência obrigatória de uma preparação para o exercício do magistério superior por parte de profissionais. Trata-se pois de um imperativo (far-se-á), ficando a critério da instituição se a oferta dessa preparação far-se-á pela forma prioritária (stricto sensu) ou pela alternativa (lato sensu). ${ }^{13} \mathrm{O}$ que a LDB dispensa, no artigo 65, não é a formação docente nem a prática de ensino (suposta no contrato para o exercício profissional), mas sim as 300 horas obrigatórias de prática de ensino. A leitura exclusiva do artigo 66 e excludente dos demais conduz a interpretações equivocadas. Basta reler com atenção o artigo 61 da LDB. Este, ao tratar da formação dos profissionais, não os recorta apenas para e na educação básica. Esse recorte será objeto do artigo 62. Os incisos I e II do artigo 61 póem como fundamentos dessa formação de um profissional da educação: "I - a associação entre teorias e práticas, inclusive mediante a capacitação em serviço; II - aproveitamento da formação e experiências anteriores em instituiçôes de ensino e outras atividades".

Muitas universidades públicas já colocam, entre as atividades do estágio probatório, a exigência dessa preparação. ${ }^{14} \mathrm{E}$ é preciso atentar que tal preparação, por ser exigida de alguém que já tem um campo profissional definido por meio de um diploma, será dada em nível de pós-gra- 
duação. Sabendo-se que a pós-graduação comporta cursos na modalidade lato sensu e de programas de mestrado e de doutorado stricto sensu, a lei coloca como primazia estes últimos e lhes dá a preferência de serem os primeiros em ordem, tempo e dignidade.

Entretanto, essas possibilidades, que significam o reforço da graduação como momento decisivo na formação universitária e profissional e na articulação com a pós-graduação, sofrem várias limitações. Além da equivocada compreensão da exigência legal de formação, há ainda a manutenção da citada "dupla rede". No âmbito da rede privada, os benefícios da criação de uma cultura de pesquisa far-se-ão presentes em médio e longo prazos, já que a expansão de universidades privadas se deu nos últimos anos. No âmbito da rede pública, são os fatores ligados ao financiamento, à burocratização e à incompreensão do teor do artigo 66 os que impedem a maior disseminação dessas iniciativas.

Em todo caso, é tarefa nova também para os estudantes reconhecer a importância de um ensino qualificado e renovado pela pesquisa e lutar pela sua instalação e/ou ampliação, cooperando institucionalmente pela diminuição das distâncias entre graduação e pós-graduação. Um estudante de pós-graduação que se envolve nas múltiplas facetas da docência ganha competência didática, amplia a compreensão do universo educacional e passa a valorizar o profissional do ensino nos sistemas de ensino. ${ }^{15}$

Para que a relação graduação/pós-graduação possa ir além da qualificação de docentes é preciso traçar uma radiografia mais detalhada da situação atual, que, com a participação de órgãos colegiados e de gestores universitários, ofereça alternativas tendo em vista uma relação mais integrada e dotada de uma circularidade virtuosa. Tal circularidade será reforçada positivamente, no processo de avaliação institucional da CAPES, se os docentes e pesquisadores credenciados atuantes na pós-graduação estiverem também presentes na graduação. Neste sentido, a existência de Fóruns Nacionais de Pró-Reitores de Graduação e de Pós-Graduação e Pesquisa pode representar um patamar institucional dessa articulação.

Outro ponto a ser considerado pelo Conselho Nacional de Educação é o da normatização, de modo preciso e objetivo, do artigo 66 da LDB no contexto maior da mesma lei e da própria legislação educacional como um todo. Daí podem derivar projetos de aperfeiçoamento do ensino de graduação que incluam novas metodologias de ensino/aprendizagem tendentes ao diálogo inter e multidisciplinar; projetos de im- 
plantação das diretrizes curriculares articuladas com projetos pedagógicos; interação planejada da graduação e pós-graduação por meio de presença em defesas de dissertação e tese, conferências, práticas de laboratório e eventos científicos.

A relação de circularidade virtuosa entre ambos os níveis é positiva tanto para a graduação como para a pós-graduação, sendo que a melhoria na primeira conduz a um mais alto desempenho dos formados em sua profissionalização e permite estudantes mais bem preparados para uma atuação dinâmica da pós-graduação.

A finalidade maior dessa relação é a garantia de um padrão de qualidade (art. $3^{\circ}$ da LDB), do padrão progressivo em vista do desenvolvimento nacional (art. $3^{\circ}$, II, da Constituição), da independência nacional (art. $4^{\circ}, \mathrm{I}$, da Constituição) e do progresso da humanidade pela cooperação entre os povos (art. 4\% , IX, da Constituição).

Uma relação, assim estabelecida, configura a universidade na sua indissociabilidade entre ensino e pesquisa e estende, a partir de docentes qualificados cientificamente, socialmente compromissados e preparados pedagogicamente, sua presença ao desenvolvimento do país, especialmente à educação básica. Ao mesmo tempo, permite que os produtos da investigação científica façam o conhecimento avançar e se estender, de modo aplicado, ao mundo profissional não-acadêmico.

A pesquisa, componente específico da pós-graduação, e o ensino, componente específico da graduação, devem caminhar juntos e articulados com o fim de permitir a mútua criatividade. De suas diferenças, de seu entrelaçamento planejado e dos respectivos produtos, a universidade poderá ganhar maior legitimidade e se beneficiar da socialização desses níveis de ensino, estendendo-os para o conjunto da sociedade.

Recebido e aprovado em setembro de 2004.

\section{Notas}

1. Ao passo que outros países da América do Sul já possuíam universidades no século XVII, o Brasil só vai conhecê-las nos anos 20 e 30 do século XX.

2. É sempre bom deixar claro que o investimento com a pós-graduação é um gasto muito maior do que com a graduação. Contudo, faltam-nos pesquisas que trabalhem detidamente sobre estes investimentos diferenciados. 
3. A pesquisa científica no Brasil teve início, no começo do século XX, em institutos voltados para o conhecimento aplicado, como é o caso de Manguinhos (RJ), Butantã (SP), Agronômico (Campinas), entre outros.

4. Não se pode esquecer do ritmo das elevadas taxas de crescimento dos anos de 1960 e 1970 .

5. Em 1995, havia 135 universidades, das quais 39 federais, 27 estaduais, 6 municipais e 63 privadas.

6. Na verdade, antes de 1995 , havia um estimulante processo participativo de avaliação institucional conhecido como Programa de Avaliação Institucional das Universidades Brasileiras (PAIUB). Aspectos do PAIUB são retomados pela Lei n. 10.861/04.

7. Trata-se de um crescimento de quase três vezes e meia. No início dos anos de 1960, o total de estudantes pouco ultrapassava a casa dos 100 mil.

8. As estatísticas do INEP contemplam esses dados que, no caso, fogem do objetivo deste artigo; cf. www.inep.gov.br.

9. O Conselho Nacional de Educação (CNE), por meio da Câmara de Educação Superior (CES), normatizou esse artigo no Parecer CNE/CES n. 553/97 e na Resolução CNE/CES n. 02/98.

10. Cf. as alterações nesse processo normativo com a sanção da Lei n. 10.861/04 e com a Portaria MEC n. 2.051/04.

11. Embora possam se discutir modos de implantação de iniciativas dessa natureza, o clima geral dessa lei tende a reforçar o ensino como momento da universidade sem desqualificar o momento da pesquisa.

12. Criados pelo decreto n. 2.306/97 (posteriormente recepcionado com alteraçóes pelo Decreto n. 3.860/01), os centros universitários devem se caracterizar pela excelência do ensino oferecido. De acordo com o Decreto n. 4.914/03 fica vedada a criação de novos centros universitários e, até dezembro de 2007 , os centros universitários existentes deverão comprovar sua capacidade de atender ao princípio da indissociabilidade entre pesquisa, ensino e extensão e assim subir para universidade ou retroceder para faculdades integradas. A consecução do 1/ 3 de mestres e doutores bem como a de 1/3 de tempo integral foram escalonadas até 2007.

13. A LDB teve dois projetos concorrentes: o da Câmara e o do Senado. A redação inicial do projeto do Senado previa, para o que viria a ser o artigo 66, que $A$ preparação para o exercício do magistério superior se faz, em nivel de pós-graduação, em programas de mestrado e doutorado, acompanhados da respectiva formação didático-pedagógica.

14. De longa data e de modo voluntário, muitas universidades oferecem o curso de metodologia do ensino superior para o conjunto das unidades de ensino.

15. Recentemente a CAPES, por meio das Portarias CAPES n. 64/02 e 21/03, obriga seus bolsistas ao estágio docente na graduação ou no ensino médio.

\section{Referências bibliográficas}

\section{BRASIL. Constituição (1988). Constituição da República Federativa do Brasil. Brasília, DF: Senado Federal, 2002.}

\section{BRASIL. Coordenação de Aperfeiçoamento de Pessoal de Nível Superior. Estatísticas da pós-graduação. Disponível em: <www.capes.gov.br>.}


BRASIL. Coordenação de Aperfeiçoamento de Pessoal de Nível Superior. Legislação e normas da pós-graduação brasileira. Brasília, DF: CAPES/ FUNADESP, 2002.

BRASIL. Lei de Diretrizes e Bases da Educação Nacional (Lei n. 9.394/ 96). Rio de Janeiro: DP\&A, 2003.

BRASIL. Plano Nacional de Educação: Lei n. 10.172/01. João Pessoa: Secretaria de Educação e Cultura da Paraíba, 2001.

BRASIL. Ministério da Educação e do Desporto. Instituto Nacional de Estudos e Pesquisas Educacionais. Sinopse estatística da educação superior: 2001. Brasília, DF: INEP/MEC, 2002.

BRASIL. Ministério da Educação e do Desporto. Instituto Nacional de Estudos e Pesquisas Educacionais. Sinopse estatística da educação superior: 2002. Disponível em: <www.inep.gov.br>. Acesso em: 2004.

BRASIL. Ministério da Educação e do Desporto. Instituto Nacional de Estudos e Pesquisas Educacionais. A educação no Brasil na década de 90: 1991-2000. Brasília, DF: INEP/MEC, 2003.

BRASIL. Brasília: MEC/CNE. Disponível em: <www.mec.gov.br> 